\title{
Assisted ventilation in severe acute asthma
}

\author{
BERNARD HIGGINS, ANDREW P GREENING, GRAHAM K CROMPTON
}

From the Respiratory Unit, Northern General Hospital, and the University Departments of Medicine and Respiratory Medicine, Edinburgh

ABSTRACT During the period 1973-85 assisted ventilation was used for the treatment of severe asthma on 48 occasions in 18 patients (one patient was ventilated 29 times). On each occasion arterial blood gas abnormalities were restored to normal as quickly as possible irrespective of peak inflation pressures. One patient was thought to be brain dead on transfer from another hospital but was ventilated for 48 hours while this diagnosis was confirmed. There was one episode of mediastinal emphysema. There were no other complications apart from transient hypotension (blood pressure $<100 / 60 \mathrm{~mm} \mathrm{Hg}$ ), which occurred on 17 occasions but did not have any sequelae. There was no relationship between hypotension and inflation pressure but there was an association between hypotension and rate of fall of arterial carbon dioxide tension. It is concluded that the risks of barotrauma during the ventilation of patients with severe asthma are theoretical or extremely small. Rapid correction of respiratory acidosis abolishes hypercapnic respiratory drive, allowing ventilation without use of muscle relaxants. It may also enable a shorter duration of ventilation, thus decreasing the likelihood of complications.

Most episodes of severe asthma respond to conventional treatment with inhaled $\beta_{2}$ adrenoreceptor agonists, intravenous aminophylline, parenteral corticosteroids, and oxygen. Occasionally, however, assisted ventilation is necessary to save life in those patients who do not respond or are moribund on admission to hospital. Mechanical ventilation has been used in the treatment of asthma for over two decades ${ }^{1}$ and facilities for ventilation should now be available to all units treating patients with asthma. Conventionally, assisted ventilation was used to correct blood gas abnormalities as quickly as possible; but more recently it has been suggested that it is more important to avoid high inflation pressures ${ }^{2}$ and to accept hypercapnia and respiratory acidosis provided that hypoxaemia is corrected. ${ }^{3}$

In this unit assisted ventilation was used in the treatment of severe asthma on 48 occasions in the period 1973-85, during which time therapeutic aims did not change. We present the results of our experience.

\section{Methods}

PATIENTS

All asthmatic patients treated by assisted ventilation

Address for reprint requests: Dr GK Crompton, Respiratory Unit, Northern General Hospital, Edinburgh EH5 2DQ.

Accepted 3 March 1986 from 1973 to 1985 are included in the analysis. Eigh- $\frac{?}{\mathbb{Q}}$ teen patients (11 female) with an age range of 13-82 years were ventilated on 48 occasions. All but one had $\frac{0}{3}$ been treated for asthma for two years or more. One $\frac{J}{5}$ patient was ventilated during her first attack of asthma. One patient, ${ }^{4}$ now aged 26 years, was ventilated on 29 occasions, two patients were ventilated twice, and the remaining patients were ventilated on $\underset{x}{\tilde{D}}$ one occasion.

The regular treatment of the patients before their 3 . admission to hospital is summarised in table 1. Hos- $\delta$ pital treatment usually comprised hydrocortisone (200 mg intravenously four to six hourly), nebulisedo salbutamol or terbutaline (5-10 mg initially and as necessary thereafter), aminophylline $(5 \mathrm{mg} / \mathrm{kg}$ as a음 slow bolus intravenous injection followed by a constant infusion of $0.5 \mathrm{mg} / \mathrm{kg}$ per hour, or the constanto infusion alone in patients known to be taking a sustained release theophylline preparation), and high ${ }_{\omega}^{N}$ concentration oxygen.

Table 1 Regular treatment being taken before admission tao hospital

\begin{tabular}{lcl}
\hline Treatment & No of patients \\
\hline Oral prednisolone & 2 \\
ACTH & 3 \\
Inhaled $\beta$ agonist & 15 \\
Inhaled steroid & 9 & 3 \\
Oral theophylline (or derivative) & 3 & 3 \\
Inhaled cromoglycate & 3 & \\
Other treatments & & \\
\hline
\end{tabular}


Table 2 . Arterial oxygen and carbon dioxide tensions $\left(\mathrm{PaO}_{2}\right.$ and $\left.\mathrm{PaCO}_{2}\right)$ immediately before start of assisted ventilation

\begin{tabular}{lcllllrl}
\hline $\mathrm{PaO}_{2} \mathrm{~mm} \mathrm{Hg}(\mathrm{kPa})$ & $n$ & $\mathrm{PaCO}_{2} \mathrm{~mm} \mathrm{Hg}(\mathrm{kPa})$ & $n^{*}$ & {$\left[H^{+}\right] \mathrm{mmol} \mathrm{l}^{-1}$} & $p H$ & $n \dagger$ \\
\hline$>90(12)$ & 22 & $>90(12)$ & 2 & $>70$ & $<.9-11.9$ & $<7.16$ & 6 \\
$70-89(9.3-11.9)$ & 8 & $70-89(9.3-11.9)$ & 11 & $60-69$ & $7.22-7.16$ & 8 \\
$50-69(6.6-9.2)$ & 10 & $50-69(6.6-9.2)$ & 16 & $50-59$ & $7.30-7.23$ & 11 \\
$30-49(4.0-6.5)$ & 8 & $30-49(4.0-6.5)$ & 18 & $40-49$ & $7.40-7.32$ & 12 \\
& & & & $20-39$ & $7.70-7.42$ & 6 \\
\hline
\end{tabular}

* $\mathrm{PaCO}_{2}$ not recorded on one occasion.

†Hydrogen ion not recorded on five occasions.

The mean duration of the exacerbation of asthma before admission to hospital was 32 hours (range 30 minutes to 10 days). The mean time from admission to endotracheal intubation was 18 hours (range $0-10$ days). In four patients on five occasions assisted ventilation was instituted immediately on admission.

The arterial blood gas data obtained immediately before ventilation are summarised in table 2 . All of the blood gas samples were taken when the patients were breathing oxygen enriched air.

\section{INDICATIONS FOR ASSISTED VENTILATION}

On 43 occasions there was prolonged respiratory distress associated with physical exhaustion. Type II respiratory failure and respiratory acidosis were present on 29 occasions. Respiratory arrest precipitated ventilation on five occasions.

\section{VENTILATION TECHNIQUE}

A volume cycled Cape ventilator was used for all patients. Adjustments to the ventilator settings were made according to body size and age. Sedation with intravenous phenoperidine was given as required to allow patients to synchronise with the ventilator. Muscle relaxants were used only at the time of endotracheal intubation. Arterial blood gas tensions and hydrogen ion concentration were restored to normal as quickly as possible. A minute volume of 10 litres was used initially for adults, usually with a rapid respiratory rate of $18-20$ a minute. High inflation pressures were ignored. The inspired oxygen tension was adjusted according to the arterial oxygen tension $\left(\mathrm{PaO}_{2}\right)$ and minute volume according to the arterial carbon dioxide tension $\left(\mathrm{PaCO}_{2}\right)$. Arterial blood gas analysis was performed at least hourly until normal blood gases had been achieved.

\section{Results}

There was a wide range of duration of ventilation from two hours to 17 days (median $24 \mathrm{~h}$, mean $38 \mathrm{~h}$ ). The mean duration of hospital stay was nine days (range 1-54 days).

The $\mathrm{PaO}_{2}$ was at least $90 \mathrm{~mm} \mathrm{Hg}(12 \mathrm{kPa})$ within two hours on all occasions. The mean time taken to achieve a normal $\mathrm{PaCO}_{2}$ was five hours (range 40 minutes to 19 hours).

The mean maximum inflation pressure was $41 \mathrm{~cm}$ $\mathrm{H}_{2} \mathrm{O}$ (range $14-74 \mathrm{~cm}$ ) and presures of over $50 \mathrm{~cm}$ $\mathrm{H}_{2} \mathrm{O}$ were recorded on 11 occasions. The patient with a low inflation pressure was ventilated because of a combination of asthma and severe corticosteroid myopathy affecting the respiratory muscles. Inflation pressures tended to be higher (mean $43.7 \mathrm{~cm} \mathrm{H}_{2} \mathrm{O}$ ) in patients with a raised $\mathrm{PCO}_{2}$ (greater than $44 \mathrm{~mm} \mathrm{Hg} \mathrm{(6}$ $\mathrm{kPa}$ )) than in those with a normal $\mathrm{PaCO}_{2}$ (mean 35.1 $\mathrm{cm} \mathrm{H}_{2} \mathrm{O}$ ). These mean maximum inflation pressures were not, however, significantly different $(\mathrm{p}<0 \cdot 1)$.

\section{MORTALITY AND COMPLICATIONS OF \\ VENTILATION}

One patient was ventilated for two days even though she was shown to be brain dead 24 hours after ventilation had been started. She had had a respiratory and cardiac arrest in another hospital and was transferred to our unit after assisted ventilation had been instituted. This patient, who was dead on arrival, was the only one who died. There were no pneumothoraces or episodes of pulmonary infection. One patient developed mediastinal and subcutaneous emphysema. Transient hypotension was the only clinically important complication recorded.

\section{BLOOD PRESSURE AND $\mathrm{PaCO}_{2}$}

A blood pressure of less than $100 / 60 \mathrm{~mm} \mathrm{Hg}$ was recorded on 17 occasions. There was an association between such hypotension and the rate of fall of $\mathrm{PaCO}_{2}(\mathrm{p}<0.05)$ (table 3).

Table 3 Number of patients with and without hypotensive episodes grouped according to rate of fall of arterial carbon dioxide tension $\left(\mathrm{PaCO}_{2}\right)$

\begin{tabular}{lll}
\hline $\begin{array}{l}\text { Rate of fall } \\
\text { in } \mathrm{PaCO}\end{array}$ & $\begin{array}{l}\text { No of patients } \\
\text { with hypotensive } \\
\text { episode }\end{array}$ & $\begin{array}{l}\text { No of patients } \\
\text { without hypotensive } \\
\text { episode }\end{array}$ \\
\hline$<5$ & 1 & 10 \\
$5-10$ & 4 & 3 \\
$>10$ & 6 & 5 \\
\hline
\end{tabular}

*Blood pressure $<100 / 60 \mathrm{~mm} \mathrm{Hg}$. 


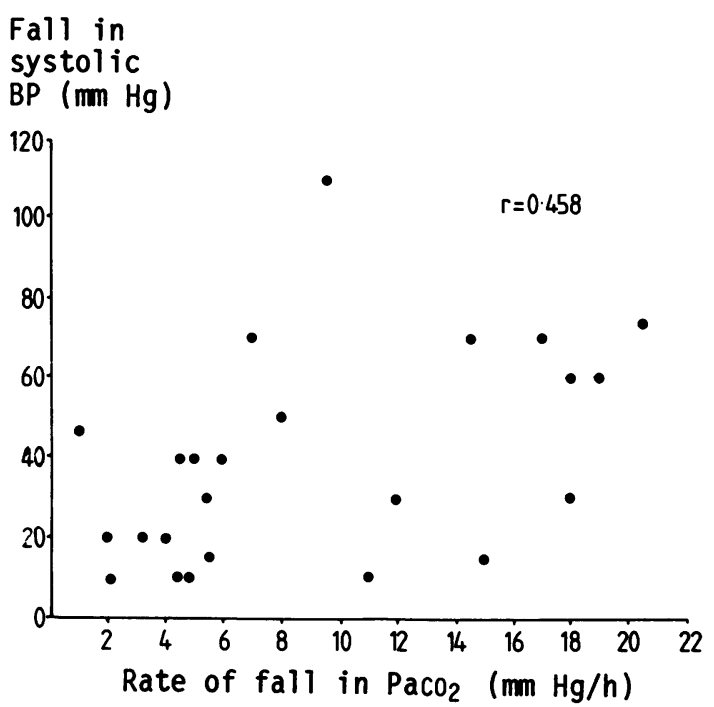

Relationship between the fall in arterial carbon dioxide tension $\left(\mathrm{PaCO}_{2}\right)$ and the fall in systolic blood pressure (BP) in 24 patients in whom there was a documented fall in systolic pressure. $(\tau=0.46, p<0.05)$. Conversion: Traditional to $\mathrm{SI}$ units- $\mathrm{PaCO}_{2}: 1 \mathrm{~mm} \mathrm{Hg} \approx 0.133 \mathrm{kPa}$.

The $\mathrm{PaCO}_{2}$ was raised on 29 occasions. Its rate of fall correlated with the fall in systolic blood pressure $(p<0.05)$-see figure.

One patient was responsible for more than half of the episodes of ventilation. Because of this the data were subjected to a $\chi^{2}$ analysis and also to the method described by Cox. ${ }^{5}$ With both analyses $\left(\chi^{2}=6.27\right.$, $\mathrm{C}=2.04$ ) there was a significant correlation between rate of fall of $\mathrm{PaCO}_{2}$ and systemic hypotension $(p<0.05)$. Thus one patient requiring ventilation on 29 occasions did not influence the group as a whole in respect of the relationship of $\mathrm{PaCO}_{2}$ and hypotension.

There was no correlation between the peak inflation pressure and either the fall in systolic blood pressure or systemic hypotension-that is, blood pressure below $100 / 60 \mathrm{~mm} \mathrm{Hg}$ (table 4).

Table 4 Number of episodes of assisted ventilation with and without hypotension grouped according to peak inflation pressure

\begin{tabular}{lll}
\hline $\begin{array}{l}\text { Peak with inflation } \\
\text { pressure }\left(\mathrm{cm} \mathrm{H}_{2} \mathrm{O}\right)\end{array}$ & $\begin{array}{l}\text { Patient episodes with } \\
B P<100 / 60\end{array}$ & $\begin{array}{l}\text { Patient episodes with } \\
B P>100 / 60\end{array}$ \\
\hline$>50$ & 4 & 7 \\
$25-50$ & 11 & 21 \\
$<25$ & 2 & 3 \\
\hline
\end{tabular}

\section{Discussion}

Eighteen patients were responsible for 48 episodes of assisted ventilation during a 12 year period. One $\frac{\bar{\sigma}}{\bar{\omega}}$ patient was ventilated for 48 hours even though she $\vec{\Phi}$

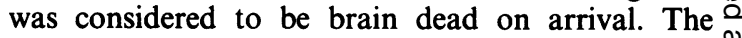
remaining 17 patients survived without clinically os important complications. Transient systemic arterial $\overrightarrow{0}$ hypotension was recorded on 17 occasions, but did not have any sequelae. It has been suggested that the $\vec{\sigma}$ complications of ventilation of patients with asthma $\vec{F}$ are related to pulmonary barotrauma caused by high $\times$ intrapulmonary pressures. ${ }^{2}{ }^{6}{ }^{7}$ For this reason it has $\doteq$ been recommended that inflation pressures of $<50$ $\mathrm{cm}$ of water should be avoided by planned assisted $\vec{\rho}$ hypoventilation, irrespective of the perpetuation of 0 respiratory acidosis in some patients. ${ }^{2}$ This approach to the ventilation of patients with asthma would be $\vec{c}$ rational only if high inflation pressures had been shown to cause serious problems such as pneumothorax. This would not appear to be the case in $\bullet$ our experience. Pneumothorax is undoubtedly a potentially lethal complication of ventilation of patients with asthma but it is uncommon. In published reports (table 5) the mortality of patients with asthma requiring ventilation ranges between zero and $\stackrel{2}{\circ}$ $38 \%$. Despite the high mortality reported by some $\stackrel{\AA}{\Omega}$ authors, however, only two patients appear to have $\overrightarrow{\overrightarrow{0}}$ died directly as a result of pneumothorax that devel- 3 oped during ventilation. ${ }^{1415} \mathrm{~A}$ more commonly reported cause of death is the development of mechanical problems with the ventilator. ${ }^{11-13}$ As such problems are more likely to occur when venti- 은 lation is prolonged reducing the time of ventilation to $\ddot{x}$ a minimum is desirable.

It has been assumed that high inflation pressures may be responsible for systemic hypotension, but in $\delta$ our patients hypotension was related to the rate of fall of $\mathrm{PaCO}_{2}$ and not high inflation pressures. Hypo- $\frac{\mathrm{O}}{2}$ tension was recorded during a high proportion of the $D$ episodes of ventilation in our patients but was not

Table 5 Previous reports of assisted ventilation in asthma

\begin{tabular}{|c|c|c|}
\hline Authors & $\begin{array}{l}\text { No of } \\
\text { episodes }\end{array}$ & Deaths \\
\hline $\begin{array}{l}\text { Darioli and Perret } 1984^{2} \\
\text { Marchand and Van Hasselt } 1966^{8} \\
\text { Riding and Ambiavagar } 1967^{9} \\
\text { Williams and Crooke } 1968^{10} \\
\text { Iisalo et al } 1969^{11} \\
\text { Sheehy et al } 1972^{12} \\
\text { Scoggin et al } 1977^{13} \\
\text { Webb et al } 1979^{14} \\
\text { Westerman et al } 1979^{15} \\
\text { Halttunen et al } 1980^{16} \\
\text { Petheram and Branthwaite } 1980^{17} \\
\text { Picado et al } 1983^{18}\end{array}$ & $\begin{array}{l}34 \\
14 \\
26 \\
18 \\
29 \\
22 \\
21 \\
20 \\
42 \\
30 \\
23 \\
26\end{array}$ & $\begin{array}{l}0 \\
3 \\
4 \\
2 \\
4 \\
2 \\
8 \\
7 \\
4 \\
3 \\
6\end{array}$ \\
\hline
\end{tabular}


associated with any observed complications. All patients showed features of good peripheral perfusion during the variable periods of hypotension and there was no evidence of renal or cerebral ischaemic age. The longest period of hypotension was 10 hours, but in most patients it was less than two hours.

Our therapeutic aim has been to achieve normal blood gas tensions as quickly as possible. In our opinion it is irrational to maintain a respiratory acidosis to avoid high inflation pressures, especially since these do not appear to cause pneumothorax. In any event high inflation pressures might be expected to be applied to the trachea and major bronchi but not the alveoli because of dissipation of such pressures by the diffuse airways obstruction and mucus plugging. Transient systemic hypotension does occur in some patients as a consequence of this approach to ventilation but is without sequelae. By returning the $\mathrm{PaCO}_{2}$ to normal as rapidly as possible we found that our patients did not have to be paralysed and they accepted assisted ventilation by a volume cycled ventilator with the aid of narcotic drugs alone. When, on the other hand, respiratory acidosis is deliberately maintained, patients need to be paralysed to facilitate ventilation. The use of muscle relaxant drugs is in itself dangerous. One reported death was considered to be due to a reaction to tubocurarine. ${ }^{9}$ Furthermore, paralysed patients are at greater risk if there are mechanical problems with the ventilator.

The advantages of avoiding paralysis and prolonged ventilation persuade us that when ventilation is required in the management of acute severe asthma it should be used to correct blood gas abnormalities as quickly as possible even though this may require the use of high inflation pressures.

We are grateful to Dr IWB Grant, who was responsible for the development of the intensive care facilities in this unit and under whose care many of the patients were treated. We are indebted to $\mathrm{Dr}$ Robin Prescott of the Edinburgh University Medical Computing and Statistics Unit for his helpful advice and to Miss IA McCall for typing the manuscript.

\section{References}

1 Leonhardt KO. Resuscitation of the moribund asthmatic and emphysematous patient. $N$ Engl J Med 1961;264:785-91.

2 Darioli R, Perret C. Mechanical controlled hypoventilation in status asthmaticus. Am Rev Respir Dis 1984;129:385-7.

3 Branthwaite M. Mechanical ventilation for severe acute asthma. Asthma Bulletin 1983;1(5):3-4.

4 Fergusson RJ, Crompton GK, Grant IWB. Severe acute asthma-a problem patient. $\mathrm{Br} J$ Dis Chest 1982; 76:301-2.

5 Cox DR. Analysis of binding data. London: Methuen, 1970:61-9.

6 Karetzky MS. Asthma mortality: an analysis of one year's experience, review of the literature and assessment of current modes of therapy. Medicine (Baltimore) 1975;54:471-84.

7 Branthwaite MA. The management of severe asthma. In: Baderman H, ed. Management of medical emergencies. Tunbridge Wells: Pitman Medical 1978:48-56.

8 Marchand P, Van Hasselt H. Last resort treatment of status asthmaticus. Lancet 1966;i:227-30.

9 Riding WD, Ambiavagar M. Resuscitation of the moribund asthmatic. Postgrad Med J 1967;43:234-43.

10 Williams NE, Crooke JW. The practical management of severe status asthmaticus. Lancet 1968;i:1081-3.

11 Iisalo EUM, Iisalo EI, Vapaavuori MJ. Prolonged artificial ventilation in severe status asthmaticus. Acta Med Scand 1969;181:51-5.

12 Sheehy AF, Dibenedeto R, Lefrak S, Lyons H. Treatment of status asthmaticus. Arch Intern Med 1972; 130:37-42.

13 Scoggin CH, Sahn SA, Petty TL. Status asthmaticus: A nine year experience. $J A M A$ 1977;238:1158-62.

14 Webb AK, Bilton RH, Hanson G. Severe bronchial asthma requiring ventilation. A review of 20 cases and advice on management. Postgrad Med J 1979;55:161-70.

15 Westerman DE, Benatar SR, Potgieter PD, Ferguson AD. Identification of the high risk asthmatic patient. Experience with 39 patients undergoing ventilation for status asthmaticus. Am J Med 1979;66:565-72.

16 Halttunen PD, Luomanmakik K, Takkunen O, Viljanen AA. Management of severe bronchial asthma in an intensive care unit. Ann Clin Res 1980;12:109-11.

17 Petheram IS, Branthwaite MA. Mechanical ventilation for pulmonary disease. A six year survey. Anaesthesia 1980;35:467-73.

18 Picado JM, Montserrat JM, Roca J. Mechanical ventilation in severe exacerbation of asthma. Eur J Respir Dis 1983;64:102-7. 